\title{
The Five Colours of Art: Non-invasive Analysis of Pigments in Tibetan Prints and Manuscripts
}

\author{
Paola Ricciardi and Anuradha Pallipurath
}

This paper reports on the preliminary results of the technical examination of two Tibetan objects in the collection of the Cambridge University Library: an illuminated manuscript, dating to the seventeenth or eighteenth century (Add. 1666), and a sixteenth-century print of the Mani bka' 'bum (Tibetan 149). ${ }^{1}$ The opportunity to undertake such investigation came about in early 2012, when the Fitzwilliam Museum launched an ambitious research project called MINIARE ${ }^{2}$ (www.miniare.org), which deals with the study of medieval and Renaissance manuscripts with a holistic, cross-disciplinary approach. While MINIARE's focus is on Western European manuscripts, the potential to expand its remit to the study of Asian material in the collections of the University Library was very tempting. In collaboration with Dr Hildegard Diemberger and the team working on the research project Transforming Technologies and Buddhist Book Culture, ${ }^{3}$ these two objects were selected to serve as initial case studies.

Knowledge of the painting materials and techniques used to decorate manuscripts and prints can provide a wealth of information on the skills and possibly the identity of the painter(s), the importance and the overall history of the object under study. It can also explain observed degradation phenomena, inform decisions regarding storage and conservation treatment, and

1 The technical analysis was carried out in December 2012 at the Fitzwilliam Museum in Cambridge, UK, with the help of Dr Jonathan M. Skelton, then a graduate student in the Department of Chemistry, University of Cambridge.

2 The miniare project is headed by the Department of Manuscripts and Printed Books at the Fitzwilliam Museum in collaboration with several Departments at the University of Cambridge and other partners. MINIARE is a cross-disciplinary endeavour, taking into account not only analytical investigations, but also the contextualization of the results within the historical, art-historical, social and political context in which the manuscripts were commissioned, executed and used.

3 http://www.socanth.cam.ac.uk/directory/research-themes/environment-time-resources/ transforming-technologies-buddhist-book-culture

(C) PAOLA RICCIARDi AND ANURADHA PALLIPURATH, 2016 | DOI 10.1163/9789004316256_023

This is an open access chapter distributed under the terms of the Creative Commons Attribution-

Noncommercial 3.0 Unported (CC-BY-NC 3.0) License, a la Ricciardi and Anuradha Pallipurath - 9789004316256 
allow for comparisons with contemporary artistic practice in other media and in other geographical areas. Despite major technical developments in recent years which allow reliable, non-invasive identification of many artists' materials (Bull et al. 2011; Delaney et al. 2010; Leona 2009; Miliani et al. 2007, 2010; Ricciardi et al. 2012; Romani et al. 2010; Rosi et al. 2010; Vagnini et al. 2009), the technical analysis of works of art on parchment and paper remains an under-developed field in comparison to the extensive analyses routinely carried out on other types of artwork, especially easel paintings (Neate et al. 2011). One main reason for this is the widespread need to employ only non-invasive analytical methods to analyse works on paper, due to the general requirement to avoid sampling, i.e. removing small portions for analysis, which is instead commonly practiced in the case of paintings on panel and canvas.

General information on pigments and painting techniques used by artists working in Tibet and in the neighbouring regions is relatively scarce, and the vast majority of it relates to thangka painting. A few scientific studies of pigments on thangkas have been published (Duffy and Elgar 2003; Elgar 2006; Ernst 2010; Laurenzi Tabasso, Polichetti and Seccaroni 2011; Mass et al. 2009), in most of which the technical analysis had been carried out on small samples removed from the paintings. The general information on Tibetan pigments and painting techniques presented in the next section is therefore mostly based on literary sources dealing with thangka painting. Very limited analytical results on other types of painted objects from Tibet have been published (Mazzeo et al. 2004; Price et al. 2009). Recently, a research project focused on the scientific investigation of Tibetan manuscripts has been started at the University of Hamburg, and its first results have just been published (Almogi et al. 2015). These technical studies seem so far to confirm the identity of the pigments used by Tibetan artists as reported by the historic and contemporary sources discussed in the following section. ${ }^{4}$

4 The characteristics of the paper on which the manuscripts were written is also of interest in order to understand Tibetan craftsmanship; paper fibre analysis of several groups of Tibetan manuscripts has been carried out and its results combined with codicological, palaeographical and textual information by Helman-Ważny and Van Schaik (2013). Additional technical research is ongoing on the related topics of identifying paper-making plants (Boesi 2014) and paper typologies (Helman-Ważny 2014) used for the production of manuscripts. 
Tibetan colour theory, as reported to us by fifteenth-century scholar Bo dong Pan chen, considers the existence of five colours: white, red, blue, yellow and black. All other colours are thought to derive from these five (Jackson and Jackson 2006: 91). One would expect then to find mentions of pigments of these five colours in historic and contemporary sources. These, however, also discuss the use of pigments of a sixth colour i.e. green (Huntington 1970:131; Jackson and Jackson 2006: 78), suggesting that mixing blue and yellow pigments to obtain green, common in other parts of the world, was not and still is not preferred by Tibetan artists. ${ }^{5}$

Historic pigments ${ }^{6}$ can be classified according to their nature as being either inorganic, of both mineral (i.e. natural) and synthetic (i.e. man-made) origin, or organic, of both vegetal and animal origin - in which case they are more accurately defined as dyes. ${ }^{7}$ Tibetan sources list the following pigments, here divided by colour:

- white: calcium compounds such as chalk and limestone (calcium carbonate, $\left.\mathrm{CaCO}_{3}\right)$;

- red: cinnabar and its synthetic analogue vermillion (mercury sulphide, $\mathrm{HgS}$ ), minium and its synthetic analogue red lead (lead tetroxide, $\mathrm{Pb}_{3} \mathrm{O}_{4}$ ), red earths and ochres, lac (the resinous secretion of a number of species of scale insects) and sandalwood (a dye extracted from a family of trees);

- blue: azurite, which is a copper-carbonate mineral $\left.\left(\mathrm{Cu}_{2}\left(\mathrm{CO}_{3}\right)_{2} \mathrm{OH}\right)_{2}\right)$, as well as indigo, derived from the leaves of a number of Indigofera and other plant species. Lapis lazuli, a semi-precious blue stone mined in the mountains of Afghanistan and widely used to produce a beautiful pigment called ultramarine blue, appears to have only been used as a medicinal substance in Tibet;

5 An extensive discussion of Tibetan painting materials is beyond the scope of this paper and therefore only a brief summary is presented here. The reader is referred to the comprehensive essay by David and Janice Jackson (Jackson and Jackson 2006), on which this section is largely based, for more information.

6 Historic pigments can be defined as those available to artists before the Industrial Revolution.

7 The term 'pigment' properly refers only to a colourant that is insoluble in water, whilst a 'dye' is a soluble colourant. In this sense, indigo is the only organic colourant which is a pigment rather than a dye. However, since colourants are commonly referred to as pigments, we will continue to use these two terms as synonyms, and use 'dye' to indicate any organic colourant. 
- yellow: arsenic sulphides i.e. orpiment $\left(\mathrm{As}_{2} \mathrm{~S}_{3}\right)$ and realgar $\left(\alpha-\mathrm{As}_{4} \mathrm{~S}_{4}\right)$, yellow earths and ochres, as well as dyes made from the petals of several plants, and from barberry and rhubarb roots;

- black: carbon-containing materials such as charcoal (wood chars) and lamp black, prepared by collecting the soot produced by burning oils and resins;

- green: the only green pigment mentioned is malachite, which is a copper-carbonate mineral $\left(\mathrm{Cu}_{2} \mathrm{CO}_{3}(\mathrm{OH})_{2}\right)$. References to yellowish-green plant-based dyes can also be found, but mostly only in the context of textile dyeing (Jackson and Jackson 1976: 288).

Many of these pigments could be sourced from specific regions in Tibet; this was the case for azurite and malachite, cinnabar, orpiment and realgar. The most common pigments, such as red and yellow earths and ochres, yellow dyes and carbon-based blacks, could be sourced from a number of sites in the region. Other pigments, such as vermillion, minium, lac dye and indigo, were instead imported into Tibet from neighbouring countries such as Nepal and China, or from India.

Additional 'modern' (i.e. post-1820) pigments listed include synthetic ultramarine, emerald green and Scheele's green. Powdered metals including gold, silver, brass and copper were also used as inks and painting materials.

A large number of analytical methods are currently used for the technical investigation of cultural heritage objects including works of art on paper such as manuscripts and prints. The most sophisticated of these, which are also the most accurate, require taking small samples from the objects. Because of the damage, however small, that this causes to the art object, these methods are more and more often being substituted by non-invasive analytical methods, which do not require sampling and can be used in situ, often without the need to even touch the object.

Such is the case of reflectance spectroscopy in the ultraviolet-visible-near infrared range (UV-Vis-NIR), which has been successfully used in recent years to identify a large number of pigments, inks and paint binders on easel paintings (Bacci et al. 2003; Delaney et al. 2010) as well as on works of art on parchment and paper (Aceto et al. 2014; Delaney et al. 2014; Ricciardi et al. 2012, 2013; Ricciardi, Pallipurath and Rose 2013; Strlič et al. 2010; Vetter and Schreiner 2014; Wouters 2008). It has the advantage of being a rapid technique (only a few seconds are required to collect each spectrum) allowing for comprehensive 
analysis of extensively decorated objects such as manuscripts, in which hundreds of illustrations might be present. Reflectance spectroscopy is often referred to as FORS when the spectrometer is equipped with fibre optics, such as the one used in the present work. ${ }^{8}$

Reflectance spectroscopy measures light that has been reflected or scattered from a surface, as a function of wavelength. In a simplified way, one can say that as light impinges onto an object, some is reflected from the surface, some is absorbed and some is scattered in a different direction and continues to interact with the material until it is either absorbed or reflected back away from the surface so that it may be detected and measured. Light is absorbed by several processes; their nature and their wavelength dependence allow deriving information about the chemical composition of an object based on its reflected light, i.e. on the shape and characteristics of the measured reflectance spectrum. The human eye functions as a crude reflectance spectrometer in the visible range (i.e. $400-700 \mathrm{~nm}$ ): we can look at a surface and see colour. The eyes and brain process the wavelength-dependent scattering of visiblelight photons and reveal a physical property of the object we are observing, i.e. colour. A spectrometer, however, can measure finer details, which allows making a distinction between different materials of the same colour. It can also work in an extended wavelength range (UV-vis-NIR) and therefore provide more information about the object's composition and molecular structure than can be seen with the eye (Aceto et al. 2014; Clark 1995).

Whilst it cannot, if used alone, identify all the possible pigments used by artists, reflectance spectroscopy is an extremely useful tool for preliminary technical investigations of painted areas on works of art, to be then supplemented by other analytical methods such as X-ray fluorescence and Raman spectroscopy.

Ultraviolet-induced luminescence imaging (also called UV imaging) was also employed to verify the identity of certain pigments on both objects. Some pigments show a characteristic appearance when viewed under ultraviolet radiation. While exact identification of pigments based on this method alone is hardly possible, UV imaging can provide useful information to supplement analytical data from other techniques. In a very simple set-up, a commercial digital camera (Canon EOS $20 \mathrm{D}$ ) was used to take photographs of the pages whilst illuminating them with an ultraviolet light source $(254 \mathrm{~nm})$.

8 FORS analysis was carried out using a FieldSpec4 spectroradiometer (manufactured by ASDi/ Panalytical, lent to us by Analytik Ltd.) with external light source, with the ability to collect reflectance spectra between 350 and $2500 \mathrm{~nm}$. 


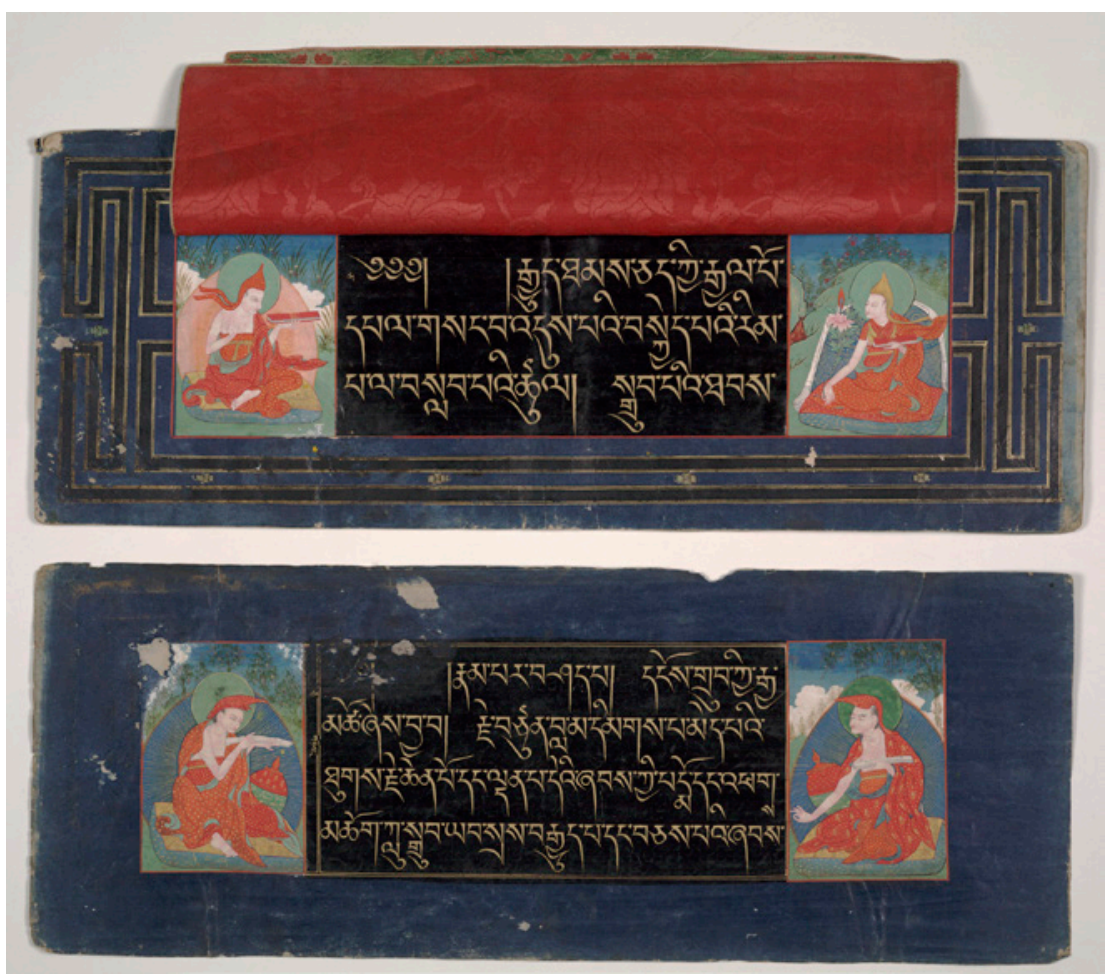

FIGURE 21.1 Cambridge University Library ms Add. 1666, folios 1 (top) and 2 (bottom).

Add. 1666

This manuscript was acquired by the Cambridge University Library (CUL) in 1876 and it is one of the most beautiful and well-preserved Tibetan texts of the CUL. The first three leaves are richly written in golden ink on black paper. The illustrations painted on the first page are protected by multiple layers of brightly coloured textiles. The rest of the book is written in silver ink with a golden line in the middle. The manuscript is 362 folios long $(220 \times 580$ [leaves], $150 \times 470$ [written], 9 lines $)$. It has the title rGyud thams cad kyi rgyal po dpal gsang ba 'dus pa'i bskyed pa'i rim pa la bslab pa'i tshul /sgrub pa'i thabs rnam par bzhed pa ngos grub kyi rgya mtsho by mKhas grub dge legs dpal bzang and is part of a collection of Tsong kha pa's writings.

The four illustrations on folios $1 \mathrm{v}$ and $2 \mathrm{r}$ (Figure 21.1) and the coloured textiles covering the first page were analysed by fibre optic reflectance spectroscopy and UV imaging. The same pigments were identified on both pages; 

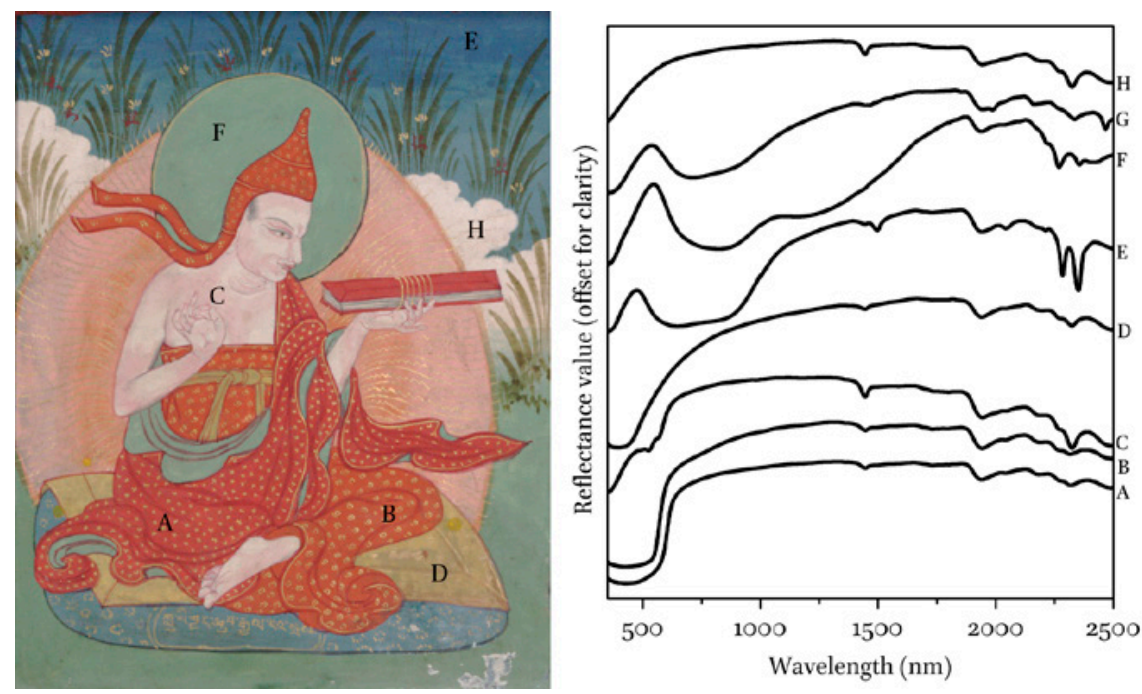

FIGURE 21.2 MS Add. 1666, detail from fol. $n$ with sites analysed and corresponding reflectance spectra.

therefore the following discussion will focus on the illustration on the left side of folio $\mathrm{iv}$ as an example of the overall results. Figure 21.2 shows sample reflectance spectra from the illustration on folio $1 \mathrm{v}$ and the areas where they were collected, each labelled with a letter to which reference is made in the discussion below.

Red areas (A) were painted using cinnabar/vermillion, characterised by a transition edge at $602 \mathrm{~nm}$. Reflectance spectroscopy cannot distinguish between the natural and the synthetic form of mercury sulphide. Orange areas (B) were painted with minium/red lead, recognisable by its transition edge at $570 \mathrm{~nm}$. The natural and the synthetic form of lead tetroxide are also indistinguishable by FORs. Pink areas (C), including fleshtones, contain an organic dye of insect origin, showing absorption maxima at 524 and $566 \mathrm{~nm}$. The spectroscopic analysis alone cannot distinguish between different kinds of red dyes derived from Coccid scale insects such as kermes, cochineal and Indian lac (Aceto et al. 2014: 1492), but the presence of lac dye can be hypothesized in this case based on what is known about traditional Tibetan painting methods (Jackson and Jackson 2006: 112-114).

Orpiment was most likely used to paint yellow areas (D). This hypothesis is based on the presence of a broad and asymmetric transition edge at about $482 \mathrm{~nm}$ in the reflectance spectrum and on the absence of fluorescence emission under UV imaging, which suggests that the pigment is indeed inorganic. 
Blue areas (E) were painted using azurite, which displays a spectrum characterised by intense absorption bands at 1493, 2283 and $2350 \mathrm{~nm}$. Green areas (F) were instead obtained with malachite, which shows very distinct absorption bands at 2218, 2270 and $2356 \mathrm{~nm}$. In some green areas on three of the illustrations on both folios $(G)$, however, the spectral signature is different and most resembles that of verdigris. ${ }^{9}$ In one of these areas the green pigment does appear darker, and its application less homogeneous. Overall there is, however, no apparent correlation between the visible appearance of each green area and its spectral signature. The nature of this second green pigment and the reason why it is only present in certain areas deserve further investigation; it is possible that it may be a trace of a past conservation treatment carried out on the manuscript.

White areas $(\mathrm{H})$ were painted with lead white (lead carbonate), recognisable by intense absorption bands at 1445 and $2324 \mathrm{~nm}$. The identification of lead white is unexpected, as this material is never mentioned by literary sources listing pigments used by Tibetan artists. It has, however, been identified during technical examinations of a late 19th or early 20 th century Tibetan altar (Price et al. 2009), of a 19th century Mongolian-style thangka (Huntington 1970: 131) and of earlier paintings on silk, paper and wall from other Eastern Asian countries, notably China, Korea and Japan (Gettens, Kühn and Chase 1993: 78; Winter 1981). The spectral signature for lead white was identified also in most sites analysed on manuscript Add. 1666, regardless of the colour of the individual areas, as well as in one area where the paint layer has flaked off the page. The data suggest that lead white may be present as a 'ground' layer, as was customary in European easel painting. Lead white is also mentioned as one of the materials being imported into Nepal and Tibet by the British East India Company in 1831 (Mass et al. 2009: 116). It is of course possible that the same Company may have imported it into Tibet much earlier than the mid-19th century. The combination of the analytical data with the latter information supports the hypothesis that both the lead white pigment and its use as a painting material for both ground and surface paint layers might have been 'imported' from Europe rather than from Eastern Asia.

Lead white, which is an inorganic pigment, was also identified in the white highlights painted over fleshtone areas, in which an organic pink base layer is present. This is, again, an unexpected result because it is traditionally believed that Tibetan artists used mainly inorganic pigments for the main paint layers,

9 These 'verdigris' areas show absorption bands at 1465, 1493, 1556, 1988, 2160, 2335 and $2467 \mathrm{~nm}$, some of which are very intense. 
and reserved organic dyes for the final highlighting and outlining stages (Jackson and Jackson 2006: 91).

The blue paper surrounding the illustrations was dyed with indigo and the black background over which the text is written was obtained with a carboncontaining pigment. FORS cannot exactly identify the metallic ink, but it does confirm that it is indeed metallic rather than a yellow pigment used to imitate gold.

Reflectance spectroscopy also allowed a rapid and non-invasive confirmation of the presence of silk in the brightly coloured textiles that cover the illustrations on the first page. Silk can be identified and distinguished from other fibres such as wool, cotton and linen by the presence of characteristic absorption features in the near infrared range (Richardson et al. 2008: 305-306).

\section{$4 \quad$ Tibetan 149}

Acquired by the Cambridge University Library in 1904, this is one of the early xylographs of Tibet, printed in Southwestern Tibet (Mang yul Gung thang) in 1521 and containing the Mani bka' 'bum, one of the most important works of Tibetan literature. The first five pages are hand-written, probably to replace missing pages. The book includes beautifully coloured illustrations, which were painted after the xylographic print had been completed by two different artists, Khepa ${ }^{10}$ Drogon and Khepa Drime, as mentioned in the colophon.

The presence of more than one painter at work is reflected in the analytical results: the four pages subjected to analysis (Figure 21.3) can be separated into two pairs (fols. $319 \mathrm{r}$ and $320 \mathrm{r}$ vs. fols. $370 \mathrm{v}$ and $37 \mathrm{rr}$ ) on the basis of the pigments identified. One illustration from each pair will be used here to summarise the analytical results and describe each artist's palette. Sample reflectance spectra from these two illustrations and the corresponding sites of analysis are shown in Figure 21.4 and labelled with pairs of letters for easier reference to the following discussion of the results.

Both artists used cinnabar/vermillion, possibly mixed with a small amount of a red earth/ochre, to paint red areas (a-A). Most orange areas have severely degraded and now have a brown and inhomogeneous appearance; this causes the reflectance spectra to be hard to interpret, though the presence of minium/ red lead is possible. Both the nature of this orange material and its degradation process deserve further investigation. Fleshtones are a light pink colour on 


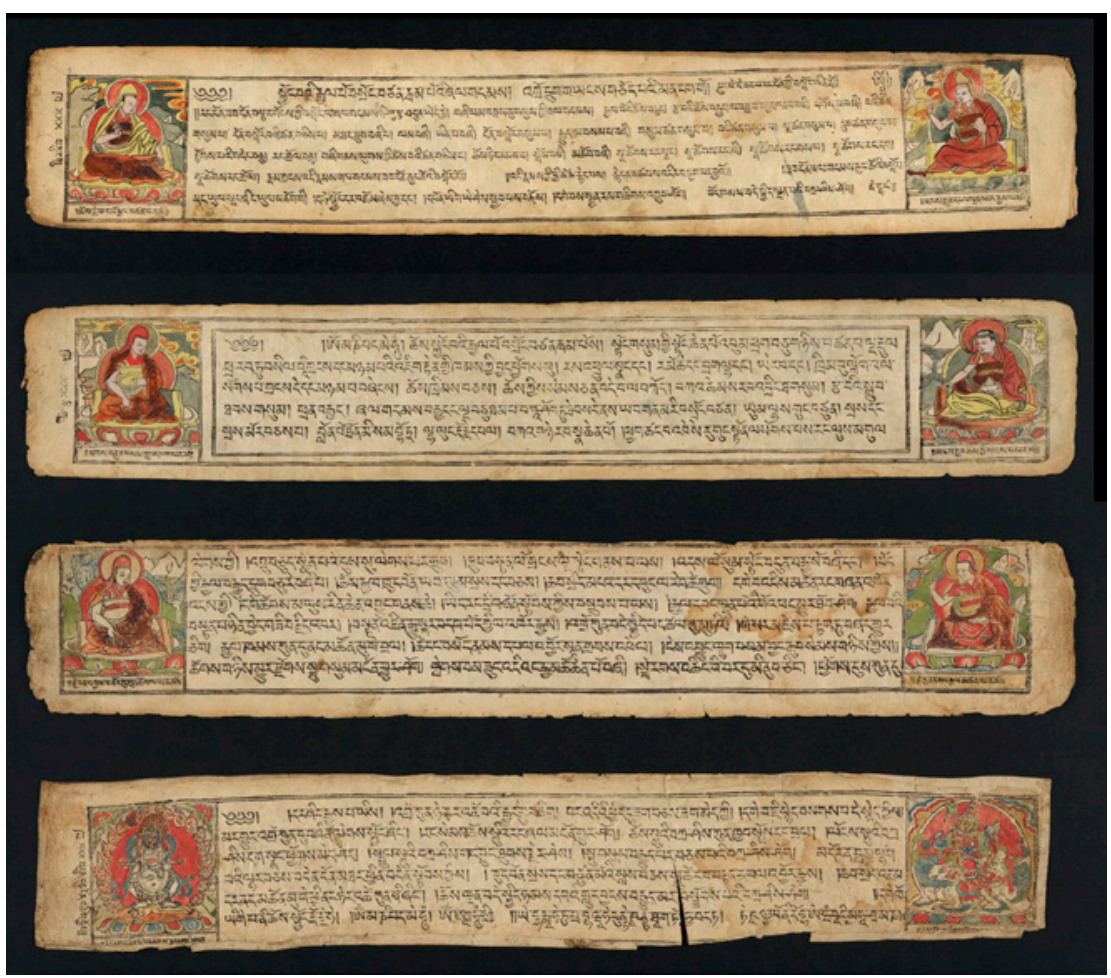

FIGURE 21.3 Cambridge University Library Ms Tibetan 149, from top to bottom: fol. 319r, fol. $320 r$, fol. $370 \mathrm{v}$ and fol. 371 r.

folios 319-320 (b), and contain a small amount of red earth/ochre ${ }^{11}$; on folios 370-371 they were probably left blank (B), as both their colour and their reflectance spectra are very similar to those of the paper. The difference in the composition of fleshtones is clearly reflected in the UV images (Figure 21.5), which display a strong difference in the fleshtones' emission on folio $319 \mathrm{r}$ (purple) and $370 \mathrm{v}$ (no emission; fleshtone areas appear just like the bare paper).

The reflectance spectra of yellow areas (c-C) show broad transition edges at about $475-480 \mathrm{~nm}$, compatible with the presence of either orpiment or an organic dye. Imaging under UV illumination (Figure 21.5) confirms that on folios 319-320 the yellow colourant is probably inorganic, therefore quite possibly orpiment, due to the absence of luminescence emission. On the other hand, the strong emission visible from the yellow areas on folios $370-371$ suggests that the yellow colourant used here is probably an organic dye.

11 Spectra acquired in these areas also show absorption bands at 1413, 2200 and $2350 \mathrm{~nm}$, whose origin is still under investigation. 


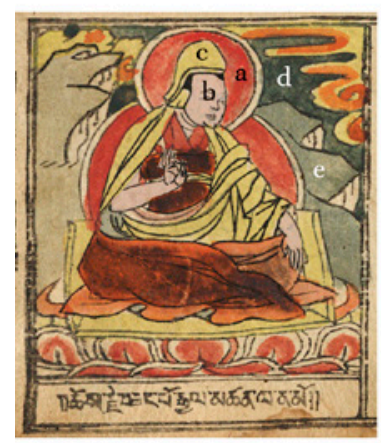

Fol. 319 (detail)

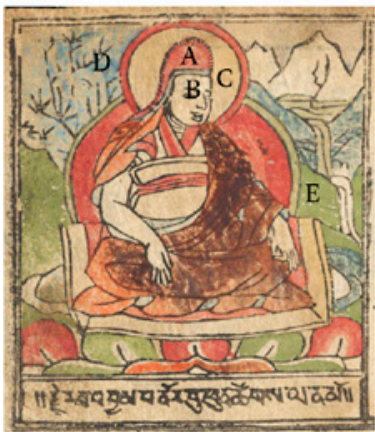

Fol. $370 v$ (detail)
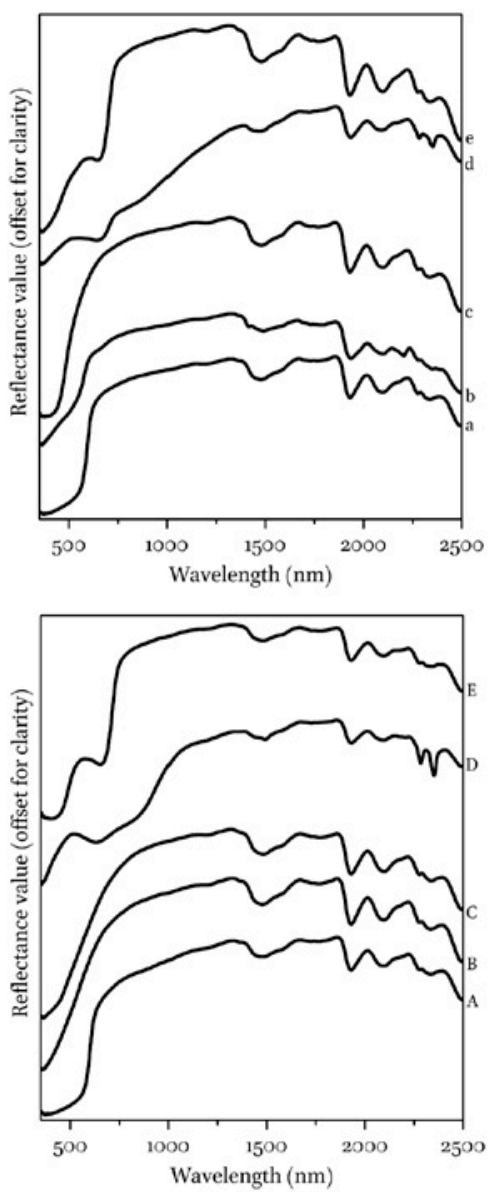

FIGURE 21.4 MS Tibetan 149, details from folios 319r (top) and 370 v (bottom) with sites analysed and corresponding reflectance spectra.
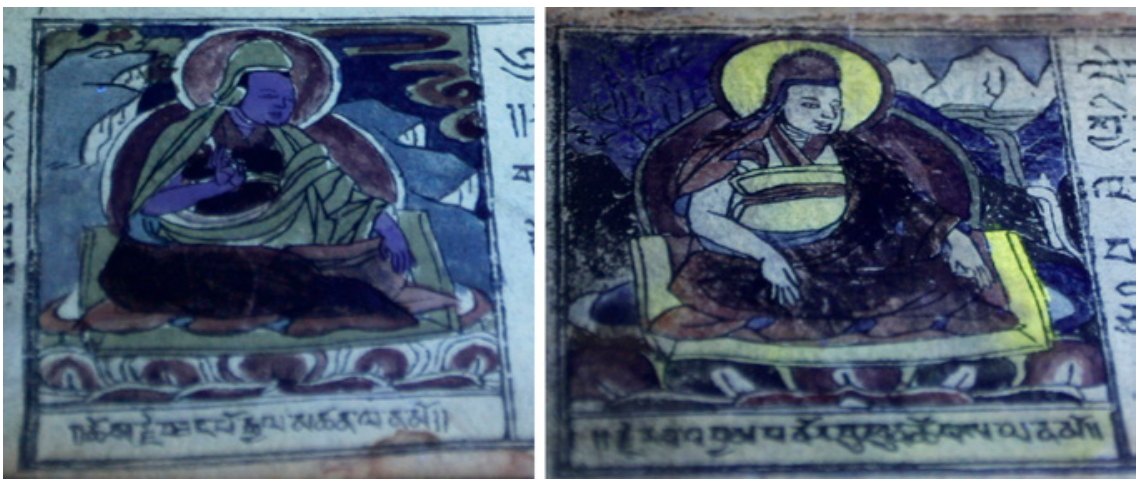

FIGURE 21.5 MS Tibetan 149, details from folios 319r (left) and $370 \mathrm{v}$ (right) imaged under UV illumination. 
Truly blue areas are only present on folios $370^{-}-371$ (D), where they were obtained with azurite, as shown by intense absorption bands at 1493, 2284 and $2350 \mathrm{~nm}$ in the reflectance spectrum. The greenish-blue hues on folios 319-320 (d) were instead obtained by either mixing or, more likely, layering azurite and indigo; the presence of indigo can be inferred from the deep absorption at about $650 \mathrm{~nm}$ followed by a rather sharp rise in reflectance.

Green areas (e-E) were most likely painted with mixtures of indigo, again identified by the deep absorption between $650-660 \mathrm{~nm}$, with yellow pigments, probably different on the two sets of pages. Further technical analysis by means of either X-ray fluorescence or Raman spectroscopy would be needed to confirm the presence of these yellow pigments and ascertain their nature.

Visual observation suggests that white areas may have been left largely unpainted; however, reflectance spectroscopy is unable to identify white calcium-based pigments such as chalk and limestone and so their presence cannot be excluded.

\section{Conclusions}

The results obtained during the preliminary technical investigation of selected pages from manuscript Add. 1666 and the Tibetan 149 xylograph highlight the potential of non-invasive scientific analysis as a tool to further our knowledge of the materials and painting techniques of Tibetan artists.

Based on these results, we need to expand on the list of pigments used by Tibetan artists, at least when discussing paintings on paper, i.e. manuscripts or hand-painted prints. Lead carbonate appears to have been the white pigment of choice for the artist decorating Add. 1666, although the presence of other (calcium-based) white pigments cannot be excluded based on the spectroscopic data alone. The use of lead white, as well as its presence in a ground layer, suggest that this artist may have had strong ties with the Western world, something which certainly deserves further investigation. Green pigments not included in the traditional lists of Tibetan artists' materials were also identified, i.e. verdigris (which may have been a later addition on Add. 1666) and green mixtures obtained with indigo and yellow pigments. We also unexpectedly identified the combined use of azurite and indigo either in a mixture or, more probably, in a sequence of layers. Finally the analytical results challenge the notion that Tibetan artists used mineral pigments exclusively for painting base layers, and organic ones for highlighting and outlining. 
Future analytical work will focus on completing the characterisation of the palette used by each artist on these two objects, by means of complementary analytical methods such as X-ray fluorescence, Fourier-Transform Infrared spectroscopy, and Raman spectroscopy. Infrared imaging of the manuscript might also reveal the presence of underdrawing and preliminary sketches.

Further analysis of a greater number of pages from Tibetan 149 may well allow assigning authorship of the decoration on each of them to one or the other artist. Additionally, if a substantial corpus of Tibetan manuscripts and prints were to be analysed in the future, we may well be able to start generalising the results obtained so far and begin to explore the relationship between artists working in Tibet and in neighbouring countries based on their use of certain painting materials and artistic techniques.

\section{Acknowledgements}

The authors wish to thank Craig Jamieson and Jill Whitelock for allowing access and examination of the University Library objects, as well as Hildegard Diemberger and Michela Clemente for facilitating the technical examination and for providing information about the Tibetan material. We also wish to thank Hiran Vegad and Analytik Ltd for the loan of the FieldSpec4 instrument and for helpful advice. Jonathan Skelton's assistance whilst carrying out the analytical investigation is gratefully acknowledged, as is Stella Panayotova's continuing encouragement and support.

\section{References}

Aceto, Maurizio, Agostino, Angelo, Fenoglio, Gaia, Idone, Ambra, Gulmini, Monica, Picollo, Marcello, Ricciardi, Paola, and John K. Delaney. 2014. "Characterisation of Colourants on Illuminated Manuscripts by Portable Fibre Optic Uv-Visible-NIR Reflectance Spectrophotometry." Analytical Methods 6: 1488-1500. doi: 10.1039/ сзау41904e.

Almogi, Orna, Kindzorra, Emanuel, Hahn, Oliver and Ira Rabin. 2015. "Inks, Pigments, Paper: In Quest of Unveiling the History of the Production of a Tibetan Buddhist Manuscript Collection from the Tibetan-Nepalese Borderlands." Journal of the International Association of Buddhist Studies 36/37: 93-117.

Bacci, Mauro, Casini, Andrea, Cucci, Costanza, Picollo, Marcello, Radicati, Bruno, and Muriel Vervat. 2003. "Non-Invasive Spectroscopic Measurements on the Il ritratto 
della figliastra by Giovanni Fattori: Identification of Pigments and Colourimetric Analysis." Journal of Cultural Heritage 4: 329-336. doi: 10.1016/j.culher.2003.09.003.

Boesi, Alessandro. 2014. "Plants used for Tibetan paper-making." In Buddha's Word: The Life of Books in Tibet and Beyond, edited by Mark Elliott, Hildegard Diemberger, and Michela Clemente, 95-97. Cambridge: Museum of Archaeology and Anthropology, University of Cambridge.

Bull, Duncan, Krekeler, Anna, Alfeld, Matthias, Dik, Joris, and Koen Janssens. 2011. "An Intrusive Portrait by Goya." Burlington Magazine CLIII: 668-673.

Clark, Roger N. 1995. "Reflectance Spectra." In Rock Physics and Phase Relations: a Handbook of Physical Constants, edited by Thomas J. Ahrens, 178-188. Washington DC: American Geophysical Union.

Delaney, John K., Zeibel, Jason G., Thoury, Mathieu, Littleton, Roy, Palmer, Michael, Morales, Kathryn M., de la Rie, E. René, and Ann Hoenigswald. 2010. "Visible and Infrared Imaging Spectroscopy of Picasso's Harlequin Musician: Mapping and Identification of Artist Materials in Situ." Applied Spectroscopy 64(6): 584-594. doi: 10.1366/000370210791414443.

Delaney, John K., Ricciardi, Paola, Glinsman, Lisha D., Facini, Michelle, Thoury, Mathieu, Palmer, Michael, and E. René de la Rie. 2014. "Use of Imaging Spectroscopy, Fiber Optic Reflectance Spectroscopy, and X-ray Fluorescence to Map and Identify Pigments in Illuminated Manuscripts." Studies in Conservation 59(2): 91-101. doi: 10.1179/2047058412Y.ooooooo078.

Duffy, Kate, and Jacki Elgar. 2003. "Five Protective Goddesses (Pancaraksha): a Study of Color Notations and Pigments." In Scientific Research in the Field of Asian Art: Proceedings of the First Forbes Symposium at the Freer Gallery of Art, edited by Paul Jett, Janet G. Douglas, Blythe McCarthy and J. W. Winter, 164-169. London: Archetype Publications Ltd.

Elgar, Jacki. 2006. "Tibetan Thang Kas: an Overview." The Paper Conservator 30(1): 99-114. doi: 10.1080/03094227.2006.9638437.

Ernst, Richard R. 2010. "In Situ Raman Microscopy Applied to Large Central Asian Paintings." Journal of Raman Spectroscopy 41: 275-287. doi: 10.1002/jrs.2443am.

Gettens, Rutherford J., Kühn, Hermann, and W. T. Chase. 1993. "Lead White." In Artists' Pigments. A Handbook of Their History and Characteristics. Volume 2, edited by Ashok Roy, 67-81. London: Archetype Publications Ltd.

Helman-Ważny, Agnieszka, and Sam Van Schaik. 2013. "Witnesses for Tibetan Craftsmanship: Bringing Together Paper Analysis, Palaeography and Codicology in the Examination of the Earliest Tibetan Manuscripts." Archaeometry 55(4): 707-741. doi: 10.1111/j.1475-4754.2012.00687.x.

Helman-Wazny, Agniezska. 2014. "Tibetan Paper and Other Supports." In Buddha's Word: The Life of Books in Tibet and Beyond, edited by Mark Elliott, Hildegard Diemberger, and Michela Clemente, 98-100. Cambridge: Museum of Archaeology and Anthropology, University of Cambridge. 
Huntington, John C. 1970. "The Technique of Tibetan Painting." Studies in Conservation 15(2): 122-133.

Jackson, David, and Janice Jackson. 1976. "A Survey of Tibetan Pigments." Kailash 4(3): 273-293.

2006. Tibetan Thangka Painting. Methods and Materials. Ithaca, NY: Snow Lion Publications, 2nd ed.

Laurenzi Tabasso, Marisa, Polichetti, Massimiliano A., and Claudio Seccaroni (eds.). 2011. Visibilia Invisibilium. Non-invasive analyses on Tibetan paintings from the Tucci expeditions. Orientalis, Museo d'Arte Orientale ‘Giuseppe Tucci', Rome.

Leona, Marco. 2009. "Microanalysis of Organic Pigments and Glazes in Polychrome Works of Art by Surface-Enhanced Resonance Raman Scattering." Proceedings of the NationalAcademy of Sciences USA 106(35):14757-14762. doi:10.1073/pnas.0906995106.

Mass, Jennifer, Huang, Jo-Fan, Fiske, Betty, Shaftel, Ann, Zhang, Xian, Laursen, Richard, Shimoda, Courtney, Matsen, Catherine, and Christina Bisulca. 2009. "Thangka Production in the 18th-21st Centuries: Documenting the Introduction of NonTraditional Materials into Himalayan Painting Practice." In Proceedings of the Forum on the Conservation of Thangkas, Special Session of the ICOM-cC 15th Triennial Conference, New Delhi, India, September 26 2008, edited by Mary Ballard and Carole Dignard. ICOM-CC.

Mazzeo, Rocco, Baraldi, Pietro, Lujàn, R., and Concezio Fagnano. 2004. "Characterization of Mural Painting Pigments from the Thubchen Lakhang Temple in Lo Manthang, Nepal." Journal of Raman Spectroscopy 35: 678-85. doi: 10.1002/jrs.1203.

Miliani, Costanza, Rosi, Francesca, Burnstock, Aviva, Brunetti, Brunetto G., and Antonio Sgamellotti. 2007. "Non-Invasive In-Situ Investigations Versus MicroSampling: a Comparative Study on a Renoir Painting." Applied Physics A 89(4): 849856. doi: $10.1007 /$ soo339-007-4222-3.

Miliani, Costanza, Rosi, Francesca, Brunetti, Brunetto G., and Antonio Sgamellotti. 2010. "In Situ Noninvasive Study of Artworks: the м Оав Multitechnique Approach." Accounts of Chemical Research 43(6): 728-738. doi: 10.1021/ar100010t.

Neate, Sarah, Howell, David, Ovenden, Richard, and A. M. Pollard, eds. 2011. The Technological Study of Books and Manuscripts as Artefacts. Oxford: Archaeopress.

Price, Beth, Malenka, Sally, Sutherland, Ken, Cuffari, Katherine, Paul, Katherine, Kingery, Anne, and Xian Zhang. 20og. "A Tibetan Polychrome Domestic Altar and Four Six-Panel Cabinets: Materials Analysis, Implications for Dating, and Conservation Treatment." In: Preprints of the 15th Triennial Meeting of the Iсом Committee for Conservation. Volume 2, edited by Janet Bridgeland, 919-925. New Delhi, India: ICOM-CC.

Ricciardi, Paola, Delaney, John K., Facini, Michelle, Zeibel, Jason G., Picollo, Marcello, Lomax, Suzanne, and Murray Loew. 2012. "Near Infrared Reflectance Imaging Spectroscopy to Map Paint Binders in Situ on Illuminated Manuscripts." Angewandte Chemie International Edition 51:5607-5610. doi: 10.1002/anie.201200840. 
Ricciardi, Paola, Delaney, John K., Facini, Michelle, and Lisha Glinsman. 2013. "Use of Imaging Spectroscopy and in Situ Analytical Methods for the Characterization fo the Materials and Techniques of 15th Century Illuminated Manuscripts." Journal of the American Institute for Conservation 52(1): 13-29. doi: 10.1179/ $0197136012 Z .0000000004$.

Ricciardi, Paola, Pallipurath, Anuradha, and Kristine Rose. 2013. "It's not Easy Being Green: a Spectroscopic Study of Green Pigments Used in Illuminated Manuscripts." Analytical Methods 5: 3819-3824. doi: 10.1039/c3ay40530c.

Ricciardi, Paola, and Anuradha R. Pallipurath. 2014. "Colours." In Buddha's Word: The Life of Books in Tibet and Beyond, edited by Mark Elliott, Hildegard Diemberger and Michela Clemente, 103-104. Cambridge: Museum of Archaeology and Anthropology. Richardson, Emma, Martin, Graham, Wyeth, Paul, and Xiaomei Zhang. 2008. "State of the Art: Non-invasive Interrogation of Textiles in Museum Collections." Microchimica Acta 162: 303-312.

Romani, Aldo, Clementi, Catia, Miliani, Costanza and Gianna Favaro. 2010. "Fluorescence Spectroscopy: a Powerful Technique for the Noninvasive Characterization of Artwork." Accounts of Chemical Research 43(6): 837-846. doi: 10.1021/argoo291y.

Rosi, Francesca, Miliani, Costanza, Clementi, Catia, Kahrim, Kenza, Presciutti, Federica, Vagnini, Manuela, Manuali, V., Daveri, Alessia, Cartechini, Laura, Brunetti, Brunetto G., and Antonio Sgamellotti. 2010. "An Integrated Spectroscopic Approach for the Non-Invasive Study of Modern Art Materials and Techniques." Applied Physics A 100: 613-624. doi: 10.1007/soo339-010-5744-7.

Strlič, Matija, Cséfalvayová, Linda, Kolar, Jana, Menart, Eva, Kosek, Joanna, Barry, Caroline, Higgitt, Catherine, and May Cassar. 2010. "Non-Destructive Characterisation of Iron Gall Ink Drawings: not Such a Galling Problem." Talanta 81(1-2):412-417. doi: 10.1016/j.talanta.2009.12.017.

Vagnini, Manuela, Miliani, Costanza, Cartechini, Laura, Rocchi, P., Brunetti, Brunetto G., and Antonio Sgamellotti. 2009. "FT-NIR Spectroscopy for Non-Invasive Identification of Natural Polymers and Resins in Easel Paintings." Analytical and Bioanalytical Chemistry 395: 2107-2118. doi: 10.1007/s00216-009-3145-6.

Vetter, Wilfried, and Manfred Schreiner. 2014. "A Fiber Optic Reflection-Uv/Vis/NIRSystem for Non-Destructive Analysis of Art Objects." Advances in Chemical Science 3(1): 7-14.

Winter, John. 1981. "Lead white in Japanese Paintings." Studies in Conservation 26(3): 89-101.

Wouters, Jan. 2008. “Coming Soon to a Library Near You?” Science 322:1196-1198. 10.1126/ science.1164991. 